There are several areas related to native heart management in patients with LVADs that warrant further investigation. First, concurrent management of surgical valvular heart disease in patients undergoing durable LVAD implantation requires more study and understanding. Aortic valve insufficiency is known to progress more rapidly in LVADsupported patients; as many as $25 \%$ of patients who have been supported for multiple years will manifest significant aortic valve insufficiency. ${ }^{4}$ This progression of aortic insufficiency is clinically important and may limit functional outcomes. A variety of surgical treatment options have been used, either at the time of the LVAD implant or after, but consensus on when and how to intervene on the aortic valve is not well defined and requires more study. Furthermore, these patients with advanced heart failure exhibit significant functional insufficiency of the mitral and tricuspid valves. While remodeling following LVAD support may eliminate some of the insufficiency, there are important subsets of patients who remain with significant mitral and tricuspid insufficiency. A better understanding of when and how to intervene on mitral and tricuspid insufficiency could potentially reduce right dysfunction and improve functional outcomes. There are no randomized studies in this area.

Medical management of right heart dysfunction in patients with LVADs is also an important frontier. Long- term oral pulmonary vasodilators may be beneficial, but studies that define these benefits are lacking. Simple questions such as whether beta-blockers remain beneficial in retarding progression of RV failure are unanswered.

Finally, LVAD support does not eliminate the ventricular dysrhythmia problems. Proper application of medical therapy for ventricular dysrhythmias as well as catheter ablative therapies remains ill defined. ${ }^{5}$ Even indications and settings for internal defibrillators are not well understood. Therefore, better knowledge regarding prevention and management of ventricular dysrhythmias during LVAD support could help improve survival.

\section{References}

1. Shaffer A, Cogswell R, John R. Future developments in left ventricular assist device therapy. J Thorac Cardiovasc Surg. 2021;162:605-11.

2. Mehra MR, Uriel N, Naka Y, Cleveland JC Jr, Yuzefpolskaya M, Salerno CT, et al; for the MOMENTUM 3 Investigators. A fully magnetically levitated left ventricular assist device_-final report. N Engl J Med. 2019;380:1618-27.

3. Rogers JG, Pagani FD, Tatooles AJ, Bhat G, Slaughter MS, Birks EJ, et al. Intrapericardial left ventricular assist device for advanced heart failure. $N$ Engl J Med. 2017;376:451-60.

4. Truby L, Garan AR, Givens RC, Wayda B, Takeda K, Yuzefpolskaya M, et al. Aortic insufficiency during contemporary LVAD support, an analysis of the INTERMACS registry. JACC Heart Fail. 2018;6:951-60.

5. Gopinathannair R, Cornwell W, Dukes J, Ellis CR, Hickey KT, Joglar JA, et al. Device therapy and arrhythmia management in left ventricular assist device recipients, a scientific statement from the AHA. Circulation. 2019;139:e967-89.

\title{
Commentary: Left ventricular assist device therapy: The time is now
}

\section{Arman Kilic, MD}

In this issue of the Journal, Shaffer and colleagues ${ }^{1}$ present a concise overview of left ventricular assist device (LVAD)

From the Division of Cardiac Surgery, The University of Pittsburgh Medical Center, Pittsburgh, Pa.

Disclosures: Dr Kilic: Medical Advisory Board, Medtronic, Inc.

The Journal policy requires editors and reviewers to disclose conflicts of interest and to decline handling or reviewing manuscripts for which they may have a conflict of interest. The editors and reviewers of this article have no conflicts of interest.

Received for publication July 30, 2020; revisions received July 30, 2020; accepted for publication July 31, 2020; available ahead of print Aug 3, 2020.

Address for reprints: Arman Kilic, MD, University of Pittsburgh Medical Center, 200 Lothrop St, Suite C-700, Pittsburgh, PA 15213 (E-mail: kilica2@upmc.edu).

J Thorac Cardiovasc Surg 2021;162:614-5

$0022-5223 / \$ 36.00$

Copyright $₫ 2020$ Published by Elsevier Inc. on behalf of The American Association

for Thoracic Surgery

https://doi.org/10.1016/j.jtcvs.2020.07.087

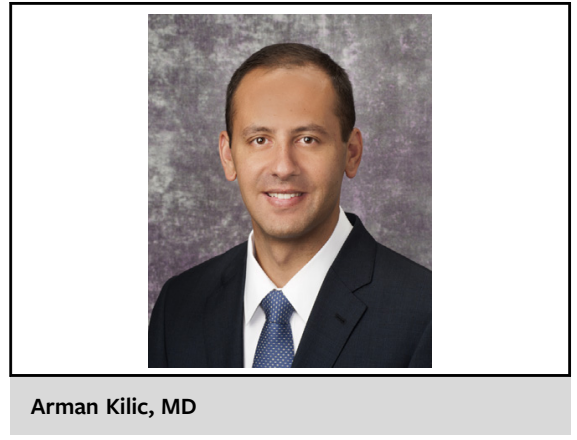

CENTRAL MESSAGE

The time is now for a random-

ized trial to prove that LVADs can

provide survival and quality of life

benefit to patients with preino-

trope ambulatory advanced

heart failure. 
therapy for advanced heart failure. The authors review major recent advancements in the field, including recent trial data, improvements in device design and surgical technique, and efforts to use newer technology including wearable devices and implantable monitors to optimize timing of support. One certainty in healthcare domains such as LVAD therapy that rely heavily on technology is constant change and evolution. A major breakthrough on the horizon is the totally implantable LVAD. This will likely improve the quality of life of patients supported with LVADs, allowing them to engage in activities limited by their driveline and eliminate the risk of driveline infections, which can be problematic. Temporary ventricular assist devices that are sternal-sparing and provide as much flow as durable LVADs are already broadly used. We will likely see the development of similar devices but with the advantage of being durable and dischargeable in coming years.

The elephant in the room remains expansion of LVAD use to less sick patients. Less than 3000 durable LVADs are implanted in patients in the United States each year despite a heart failure prevalence of 6.5 million and upwards of 250,000 patients with advanced heart failure who have low quality of life and heart failure readmissions and could potentially benefit from implantation. ${ }^{2,3}$ The latest annual report from the Interagency Registry for Mechanically Assisted Circulatory Support demonstrates that less than $15 \%$ of LVADs currently implanted are done so in patients with preinotrope Interagency Registry for Mechanically Assisted Circulatory Support profile 4 to 7 . $^{4}$

Perhaps the most effective way to convince referring physicians and the community at-large that LVADs can be beneficial for ambulatory patients with preinotrope heart failure is a randomized trial of LVADs versus optimal medical management in this population. This is not a new concept because the REVIVE-IT trial aimed to do just this and was near fruition, but was halted primarily because of concomitant reports demonstrating unfavorable rates of pump thrombosis and stroke with LVAD therapy. ${ }^{5}$ Since that time, device technology and patient management have improved as evidenced by the latest trial data of the newest generation devices. The MOMENTUM 3 trial demonstrated a $77 \%$ rate of freedom from mortality, disabling stroke, or pump removal or exchange for malfunction at 2 years. ${ }^{6}$ This is in conjunction with nonrandomized observational studies and registry data demonstrating improvements in survival and quality of life with LVAD therapy compared with medical management in this less sick cohort. $^{7,8}$ To many, compiling the existing data with contemporary devices provides enough justification and clinical equipoise to support such a randomized trial, particularly in higher-risk patients with preinotrope heart failure, including those with functional limitations, heart failure readmissions, or low quality of life.

This is an exciting time for LVAD therapy. Devices are better, our surgical technique is better, and our understanding and ability to manage patients on LVAD support are better. The time is now to randomize LVADs to optimal medical management and extend this lifesaving modality to a larger population of patients with advanced heart failure.

\section{References}

1. Shaffer A, Cogswell R, John R. Future developments in left ventricular assist device therapy. J Thorac Cardiovasc Surg. 2021;162:605-11.

2. Benjamin EJ, Blaha MJ, Chiuve SE, Cushman M, Das SR, Deo R, et al. Heart disease and stroke statistics-2017 update: a report from the American Heart Association. Circulation. 2017;135:e146-603.

3. Asleh R, Schettle SS, Khan FW, Kushwaha SS. Left ventricular assist devices as destination therapy in stage D heart failure. J Geriatr Cardiol. 2019;16: 592-600.

4. Kormos RL, Cowger J, Pagani FD, Teuteberg JJ, Goldstein DJ, Jacobs JP, et al The Society of Thoracic Surgeons intermacs database annual report: evolving indications, outcomes, and scientific partnerships. Ann Thorac Surg. 2019; 107:341-53.

5. Pagani FD, Aaronson KD, Kormos R, Mann DL, Spino C, Jeffries N, et al. The NHLBI REVIVE-IT study: understanding its discontinuation in the context of current left ventricular assist device therapy. J Heart Lung Transplant. 2016;35: 1277-83.

6. Mehra MR, Uriel N, Naka Y, Cleveland JC, Yuzefpolskaya M, Salerno CT, et al. A fully magnetically levitated left ventricular assist device - final report. $N$ Engl J Med. 2019;380:1618-27.

7. Starling RC, Estep JD, Horstmanshof DA, Milano CA, Stehlik J, Shah KB, et al Risk assessment and comparative effectiveness of left ventricular assist device and medical management in ambulatory heart failure patients: the ROADMAP study 2-year results. JACC Heart Fail. 2017;5:518-27.

8. Shah KB, Starling RC, Rogers JG, Horstmanshof DA, Long JW, Kasirajan V, et al Left ventricular assist devices versus medical management in ambulatory heart failure patients: an analysis of INTERMACS profiles 4 and 5 to 7 from the ROADMAP study. J Heart Lung Transplant. 2018;37:706-14. 